\title{
Pharmacotherapeutics for bariatric surgery patients in the primary care setting: An overview for nurse practitioners
}

\author{
Karen Stoll Abate ${ }^{* 1}$, Terry Mahan Buttaro ${ }^{2}$ \\ ${ }^{1}$ Simmons College, Boston Massachusetts, United States \\ ${ }^{2}$ University of Massachusetts, Boston, United States
}

Received: March 6, 2014

DOI: $10.5430 /$ cns.v3n1p41
Accepted: November 3, 2014 Online Published: November 18, 2014

URL: http://dx.doi.org/10.5430/cns.v3n1p41

\begin{abstract}
Patients who have undergone bariatric procedures for weight loss are increasingly seen in the primary care setting. Due to the unique characteristics of surgical weight loss procedures, the prescribing practices of health care providers must be evaluated. This article addresses the anatomical changes associated with laparoscopic adjustable gastric banding, Roux-en-Y gastric bypass, biliopancreatic diversion with a duodenal switch, and vertical sleeve gastrectomy, because absorption, distribution, metabolism and excretion of medications may be more complex for bariatric surgery recipients than for other patients. Associated prescribing modifications for primary care providers caring for bariatric surgery recipients in the primary care setting are also discussed.
\end{abstract}

Key Words: Bariatric surgery, Pharmacotherapy, Prescribing, Nurse practitioner

\section{Introduction}

Weight gain and obesity are increasingly common health conditions that nurse practitioners encounter in their practice settings. The Centers for Disease Control notes that obesity has increased triple fold over the last 20 years in American adults. ${ }^{[1]}$ Demographic data demonstrates that $67 \%$ of Caucasians, $77 \%$ of African Americans and $79 \%$ of Hispanics are considered to be overweight or obese in the United States. ${ }^{[2]}$ In America, the prevalence of obesity in adults, from 2009 to 2010 , was $35.5 \%$ in males and $35.8 \%$ in women. ${ }^{[3]}$ Worldwide, body mass index (BMI) has also increased since 1980. ${ }^{[4]}$ In America, the prevalence of obesity in adults, from 2009 to 2010, was 35.5\% in males and 35.8\% in women. ${ }^{[3]}$ Elevated BMI and obesity has also become an issue of concern with children and adolescents. Obesity affects approximately $17 \%$ of children and teens in the United States. ${ }^{[1]}$

\section{Impact}

Common chronic conditions affecting overweight and obese individuals include cardiovascular disease, cerebral vascular accidents, hypertension, diabetes and some cancers. Joint related problems such as lower back and knee pains, as well as foot issues, are also associated with patients who have an elevated BMI. Most, if not all, of these aforementioned considerations are preventable. The economic effects of obesity and being overweight have primary and secondary effects both for the individual and the health care system that

\footnotetext{
*Correspondence: Karen Stoll Abate; Email: Karen.abate2@simmons.edu; Address: Simmons College, Boston Massachusetts, 300 Fenway,
} Boston, MA 02115,United States. 
should not be overlooked. According to the CDC, the medical costs associated with obesity in the U.S. alone were a staggering $\$ 147$ billion in $2008 .^{[5]}$ Additionally, Masters et al determined that $18.2 \%$ of deaths in the U.S. between 1986 and 2006 were related to being overweight or obese. $^{[6]}$ In this study that analyzed the mortality risk of obesity based on sex, race, age, and birth cohort, the risk of death in Black women was $27 \%$ compared to White women $(21 \%)$; in Black men there was a $5 \%$ mortality risk vs White men $(15 \%){ }^{[6]}$

\section{Surgical treatment}

Weight loss surgery is one potential treatment option for patients with clinically severe obesity (BMI no less than 40) or the serious comorbid illnesses associated with a BMI no less than 35. ${ }^{[7]}$ Bariatric surgery for weight loss has grown significantly over the past $10-15$ years. Multiple studies have identified that these surgical procedures have been very effective in terms of weight loss and the associated reduction of comorbidities. ${ }^{[8,9]}$ As a result, nurse practitioners will continue to encounter bariatric surgery recipients in their practice settings. This article will summarize the most common bariatric weight loss procedures, review the current pharmacokinetic concerns in bariatric surgery recipients, and address implications for prescribing practices for primary care providers caring for patients who have undergone bariatric surgery.

\section{Bariatric surgical procedures}

The first surgery to promote weight loss was performed almost 50 years ago. This surgical procedure known as a jejunoileal bypass was, like subsequent bypass procedures, designed to decrease carbohydrate absorption and promote weight loss. Unfortunately the jejunoileal bypass was associated with malabsorption and liver failure in some patients. ${ }^{[10]}$ Since that time, surgeons have devised newer techniques to enable patients with obesity to lose weight gastric banding, gastric sleeve, gastric bypass, and the biliopancreatic diversion with a duodenal switch. These surgical interventions are indicated in patients for whom other weight loss measures have proven ineffective.

Laparoscopic Adjustable Gastric Banding (LAGB), Rouxen-Y gastric bypass (RYGB), biliopancreatic diversion with a duodenal switch (BPD-DS), and vertical sleeve gastrectomy are the four surgical weight loss options commonly used in the U.S. at this time. Laparoscopic adjustable gastric banding and the vertical sleeve gastrectomy are restrictive bariatric procedures. The RYGB and the BPD-DS are considered restrictive as well as malabsorbtive bariatric weight loss procedures. Surgical procedures that involve a combination of these approaches or more in depth anatomical adaptations will result in a greater overall weight loss for the patient.

With LAGB the newly formed gastric pouch volume can range from one to four ounces based upon how much saline has been injected into the adjustable loop. ${ }^{[11]}$ The restrictive effects of the pouch volume and the associated narrowed passage diameter, limit the quantity of food and drink tolerated by the patient at one time. Wee found that the 10 -year average weight loss for patients, who have undergone the LAGB, is $13 \%$. ${ }^{[8]}$

Table 1: Bariatric surgery comparison

\begin{tabular}{|c|c|c|c|c|}
\hline & $\begin{array}{l}\text { Laparoscopic Adjustable } \\
\text { Gastric Banding (LAGB) }\end{array}$ & $\begin{array}{l}\text { Vertical sleeve } \\
\text { gastrectomy (VSD) }\end{array}$ & $\begin{array}{l}\text { Biliopancreatic diversion with } \\
\text { a duodenal switch (BPD-DS) }\end{array}$ & $\begin{array}{l}\text { Roux-en-Y gastric bypass } \\
\text { (RYGB) }\end{array}$ \\
\hline Dietary Effects & Restrictive $\&$ Reversible $^{[11]}$ & $\begin{array}{l}\text { Restrictive \& } \\
\text { Irreversiblez }^{[14]}\end{array}$ & $\begin{array}{l}\text { Restrictive, Malabsorbtive \& } \\
\text { Irreversible }^{[14]}\end{array}$ & $\begin{array}{l}\text { Restrictive, Malabsorbtive \& } \\
\text { Irreversible }^{[12]}\end{array}$ \\
\hline Procedure & $\begin{array}{l}\text { Adjustable band placed } \\
\text { around proximal portion of } \\
\text { stomach creating small pouch; } \\
\text { constricted passage to the } \\
\text { lower portion of the stomach } \\
\text { formed }^{[11]}\end{array}$ & $\begin{array}{l}\text { Greater curvature of } \\
\text { the stomach stapled } \\
\text { and removed }\end{array}$ & $\begin{array}{l}20-30 \mathrm{ml} \text { pouch in proximal } \\
\text { stomach surgically created and } \\
\text { connected to a portion of the } \\
\text { jejunum thereby bypassing the } \\
\text { majority of the stomach, } \\
\text { duodenum and the first portion } \\
\text { of jejunum }^{[14]}\end{array}$ & $\begin{array}{l}\text { Surgical removal of } \\
\text { approximately } 70 \% \text { of the } \\
\text { stomach; pylorus valve remains } \\
\text { intact while the remaining } \\
\text { section of the stomach is } \\
\text { anastomosed to ileum }^{[12]}\end{array}$ \\
\hline $\begin{array}{l}\text { Potential } \\
\text { Nutritional } \\
\text { Deficiency }\end{array}$ & none & $\begin{array}{l}\text { Potential vitamin } \\
\text { deficiencies }\end{array}$ & $\begin{array}{l}\text { Calcium, iron, vitamin B12, } \\
\text { vitamin B1, folic acid } \\
\text { deficiencies, and vitamin A, D, } \\
\text { E \& K }{ }^{[16]}\end{array}$ & $\begin{array}{l}\text { Calcium, iron, vitamin B12, } \\
\text { vitamin B1, folic acid } \\
\text { deficiencies, and vitamin A, D, } \\
\text { E \& K }{ }^{[16]}\end{array}$ \\
\hline $\begin{array}{l}\text { Gastric Surface } \\
\text { Area \& Size }\end{array}$ & Unaffected & Decreased & Decreased & Decrease \\
\hline Gastric Acidity & Unaffected & Decreased ${ }^{[14,15]}$ & Decreased $^{[14,15]}$ & Decreased $^{[14,15]}$ \\
\hline $\begin{array}{l}\text { Intestinal Surface } \\
\text { Area \& absorption }\end{array}$ & Unaffected & Unaffected & Decreased ${ }^{[13]}$ & Decreased ${ }^{[13]}$ \\
\hline
\end{tabular}


In patients with a Vertical sleeve gastrectomy (VSG), intake digestion and nutrient absorption is slowed significantly as a result of the space restriction created by the newly created gastric sleeve. ${ }^{[12]}$ Due to the removal of the greater curvature of the stomach with VSG, the portion of the stomach that produces the hormone ghrelin is removed. ${ }^{[11]}$ The lack of the ghrelin hormone results in increased feeling of satiety. Individuals who have undergone this surgical procedure must eat small frequent meals due to the limited capacity of the newly adapted stomach.

The Roux-en-Y bariatric surgery has become the gold standard among the various weight loss surgery options. ${ }^{[13]}$ Wee noted that the 10-year weight loss for these patients is $25 \%$. ${ }^{[8]}$

The BPD-DS, involves surgical removal of approximately $70 \%$ of the stomach. ${ }^{[12]}$ The recipient's pylorus valve remains intact while the remaining section of the stomach is anastomosed to ileum. ${ }^{[12]}$ In BPD-DS surgery, both the duodenum and jejunum are bypassed which is far greater than bypassed in the Roux-en-Y procedure.

As a result of the alimentary canal surgical modifications with the Roux-en-Y gastric bypass and the biliopancreatic diversion with a duodenal switch, there are anatomical and physiological alterations that must be considered with these patients (see Table 1).

\section{Review of literature}

Understanding pharmacodynamics and pharmacokinetics of medications prescribed for individuals who have had any form of gastric weight loss surgery is essential for all healthcare professionals. However, for providers caring for patients who have had bariatric surgery comprehending the absorption, distribution, metabolism and excretion of medications may be more complex than for other patients. Studies concerning drug absorption after bariatric surgery are limited, but the anatomical and physiologic variations that result from bariatric procedures can have an effect on these physiological dimensions. ${ }^{[17,18]}$

To address these concerns, a systematic review of literature surrounding pharmacological considerations relative to bariatric surgery patients is presented. The key search terms were bariatric surgery, medication, pharmacokinetic, pharmacodynamics and pharmacotherapeutics. These terms were used to perform a literature search in multiple databases including Medline, PubMed, CINAHL, and Ovid. Eligibility criteria included the articles being published in the last seven years. All English language literature that addressed bariatric surgery, medication, and pharmacology was included. Based upon these key words and search criteria results yielded twenty-five studies which were reviewed.

Table 2: Pharmacokinetic changes after bariatric surgery

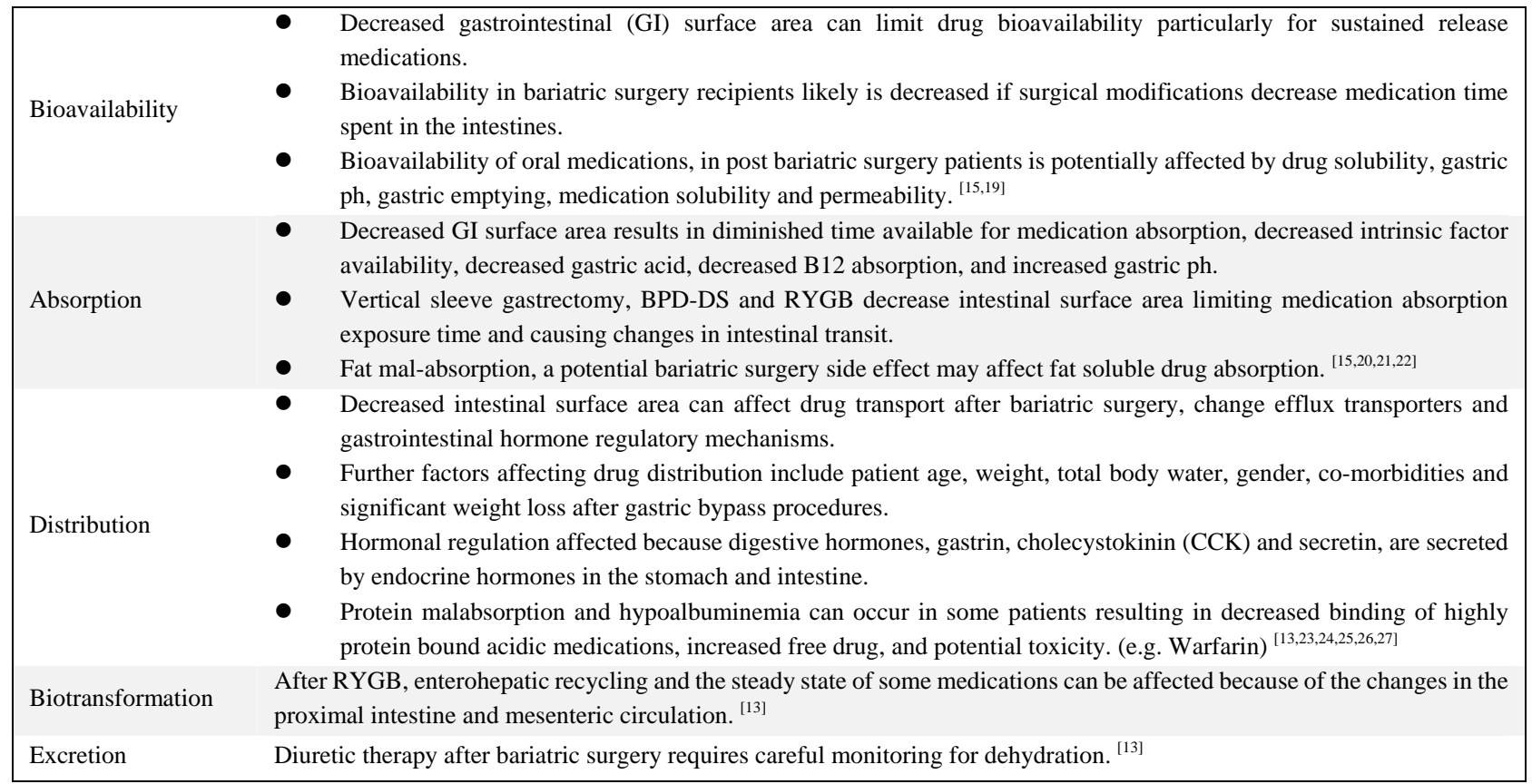

Pharmacodynamics and pharmacokinetic changes after bariatric surgery

Despite the number of patients who have had bariatric surgery in recent years, there are few studies addressing

Published by Sciedu Press

the pharmacodynamics and pharmacokinetic effects of these procedures on the medications prescribed for these patients. Many reports discuss observable data and the importance of monitoring patient responses to medications. These and the few research studies are primarily concerned with the 
pharmacokinetic effects of bariatric surgery on drug absorption, distribution, biotransformation and elimination. There is minimal research data available discussing drug effects, the pharmacodynamics, on these patients.

How quickly and to what extent an unchanged drug reaches the systemic circulation is its bioavailability. Intravenous medications have $100 \%$ bioavailability, but drugs taken orally are not absorbed completely, thus, their bioavailability is always less than $100 \%$. Because oral drugs are ab- sorbed in the gastrointestinal (GI) tract, the structural GI alterations associated with bariatric surgery can affect drug bioavailability as well as nutrient and vitamin absorption. The primary causes are poor gut absorption and decreased vascular blood supply, but first pass elimination is an additional impediment because the liver metabolizes drugs and in some instances discharges drugs into the bile. Absorption and distribution are the most affected pharmacokinetic changes after bariatric surgery, but biotransformation and excretion are also affected (see Table 2).

Table 3: Recommendations based upon current literature

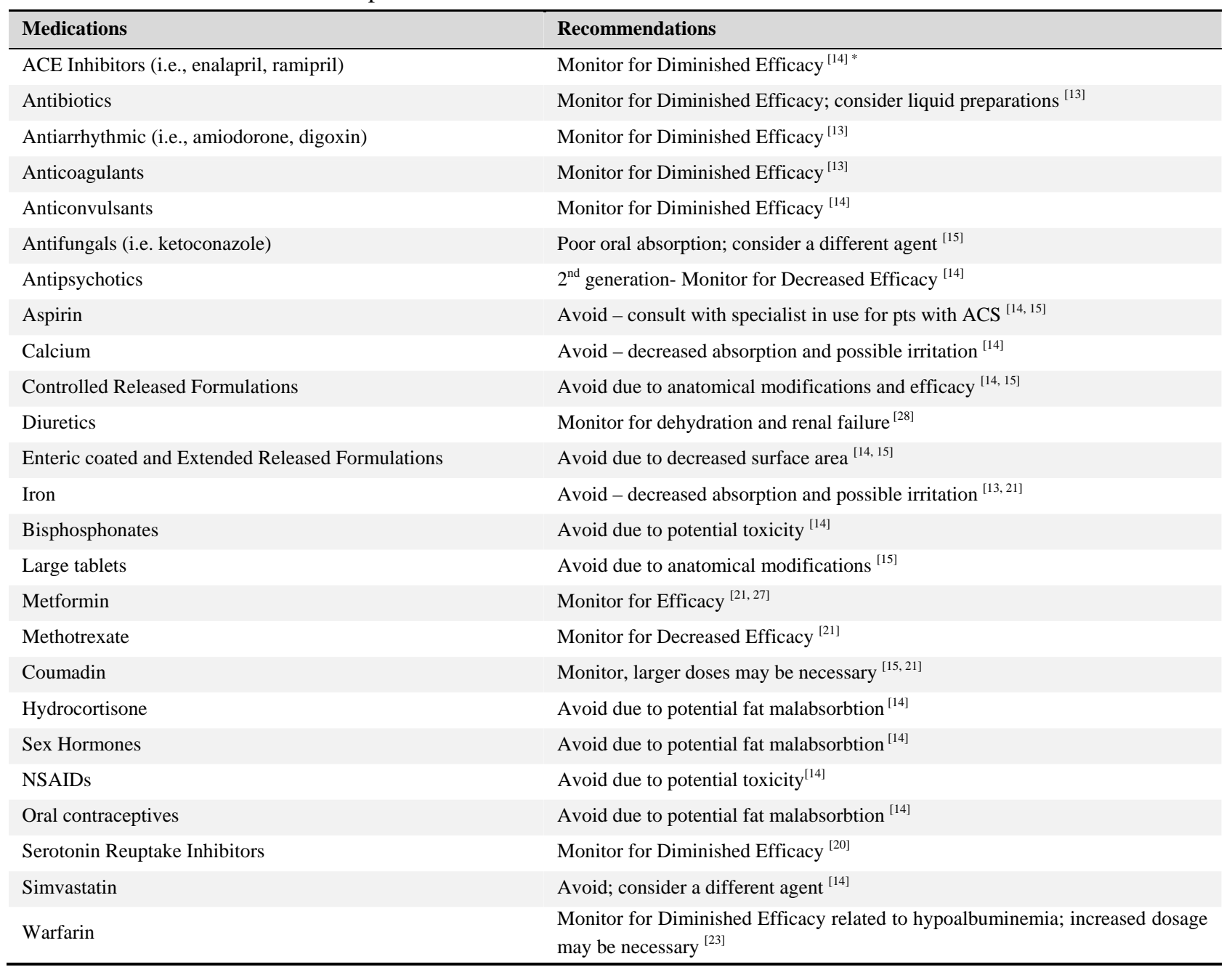

*Not all medications in this category are affected

\section{Summary of evidence}

As noted above, studies surrounding prescribing for postsurgical weight loss patients is growing but remains somewhat limited. An in depth past surgical history and nutritional evaluation should be obtained for all post bariatric surgery patient requiring any medication. Factors such as the precise surgical procedure performed, as well as related dietary modifications and intolerances should be obtained. Regardless, there are potential prescribing recom- mendations based upon current literature (see Table 3).

All post bariatric surgery patients should be closely monitored for therapeutic effects and side effects, as bioavailability, absorption and distribution of medications will vary. This is especially important for medications with a narrow therapeutic index between therapeutic and toxic dosing. ${ }^{[30]}$ Yet again, patients must be educated surrounding the desired and unwarranted effects of the medication so that they might also self-monitor effectiveness. 
Researchers at the University of Pittsburgh noted that following Roux-en-Y gastric bypass, patients who had been treated with serotonin reuptake inhibitors (SRIs) for depression seemed to regress. ${ }^{[29]}$ Hamad, et al. obtained blood samples from 12 patients before surgery, then again one month, 6 months, and 12 months after surgery to measure the SRI levels pre and post Roux-en-Y gastric bypass and determine bioavailability. ${ }^{[29]}$ Using the blood concentration curve (AUC) to measure medication bioavailability, the results of this study revealed that in $2 / 3$ of the 12 patients, AUC levels one month after surgery averaged a 54\% decrease from the preoperative baseline. ${ }^{[29]}$ At three months, the AUC levels had normalized in 6 of the 8 patients who experienced decreased levels at one month. ${ }^{[29]}$ Four patients experienced an increase in depression symptoms, but in three of the four the symptoms abated. ${ }^{[29]}$

Padwal, et al. compared metformin absorption in 16 post RYGB bariatric surgery patients with 16 control patients matched by BMI and gender. ${ }^{[27]}$ These researchers hypothesized that metformin bioavailability would be decreased in the patients who had bariatric surgery, but in fact metformin absorption and bioavailability was increased. ${ }^{[27]}$ For bariatric patients requiring diuretic therapy, vigilance is necessary to prevent dehydration and renal insufficiency. ${ }^{[28]}$

\section{Conclusions}

Weight loss surgery has grown as a potential treatment option for select obese and overweight patients in primary care. In this article, four of the most common surgical approaches are discussed. Each of these has very unique approaches and anatomical modifications which it employs. For most bariatric surgery patients, these modifications result not only in weight loss but lifestyle modifications that will last a lifetime. Healthcare providers need to be cognizant of the effect these procedures will have on our therapeutic prescribing practices.

\section{References}

[1] Centers for Disease Control and Prevention. Obesity and overweight for professionals: data and statistics: facts - DNPAO - CDC. 2012; Available from: http://www.cdc.gov/obesity/data/f acts.htm 1

[2] National Institute of Diabetes and Digestive and Kidney Diseases (2012). Overweight and obesity statistics. NIH Publication No. 044158.

[3] Flegal KM, Carroll MD, Kit BK, et al. Prevalence of obesity and trends in the distribution of body mass index among US adults 1999. 2010. JAMA. 2012; 307: 491-497.

[4] Finucane MM, Stevens GA, Cowan MJ, et al. National, regional, and global trends in body - mass index since 1980: systematic analysis of health examination surveys and epidemiological studies with 960 country-years and 9.1 million participants. Lancet. 2012; 377: 557-67. http://dx.doi.org/10.1016/S0140-673 6 (10) $62037-5$

[5] Centers for Disease Control and Prevention. Obesity and overweight for professionals: adult: causes - DNPAO - CDC, 2012; Available from: http://www.cdc.gov/obesity/adult/causes/i ndex.html

[6] Masters RK, Reither EN, Powers DA, et al. The impact of obesity on US mortality levels: the importance of age and cohort factors in population estimates. Amer J Pub Health. 2013; 103(10): 1895 1901. PMid:23948004. http://dx.doi .org/10.2105/AJPH. 20 13. 301379

[7] National Heart, Lung, and Blood Institute. The practical guide identification, evaluation, and treatment of overweight and obesity in adults. 2000.

[8] Wee CC. A 52-year-old woman with obesity: Review of bariatric surgery. JAMA. 2009; 302(10): 1097-1104. http://dx.doi.org /10.1001/jama.2009.1197

[9] Huang CY, Hsu MC, Pan CK, et al. Early health status and health - related quality of life after laparoscopic gastric bypass surgery in morbidly obese patients. Bariatric Nursing and Surgical Patient Care. 2009; 6(4).

[10] Love AL, Billett HH. Obesity, bariatric surgery, and iron deficiency: true, true, true and related. Amer J Hem. 2008; 83(5): 403-409. PMid:18061940. http://dx.doi.org/10.1002/ajh. 21106

[11] Kaser NJ, Kukla A. Weight loss surgery. Journal of Issues in Nursing. 2009; 14(1).

[12] Gagnon L, Karwacki Sheff EJ. Outcomes and complications after bariatric surgery. AJN. 2012; 112(9).

[13] Smith A, Henriksen B, Cohen A. Pharmacokinetic considerations in Roux-en-Y gastric bypass patients. Amer J Health - System Pharmacy. 2011; 68(23): 2241-7. PMid:22095812. http://dx.doi.o rg/10.2146/ajhp100630

[14] Miller AD, Smith KM. Medication and nutrient administration changes after bariatric surgery. Amer J Health - System Pharmacy. 2006; 63(19): 1852-1857. PMid:16990631. http://dx.doi.org /10.2146/ajhp060033

[15] Titus R, Kasteneier A, Otterson MF. Consequences of gastrointestinal surgery on drug absorption. Nutr Clin Pract. 2013; 28(4): 429436. PMid:23835364. http://dx.doi.org/10.1177/0884533 613490740

[16] Powell MS, Fernandez AZ. Surgical treatment for morbid obesity: The laproscopic Roux-en-Y gastric bypass. Surgical Clinics of North America. 2011; 91: 1203-1224. PMid:22054149. http: //dx.doi.org/10.1016/j.suc. 2011.08.013

[17] Edwards A, Ensom MH. Pharmacokinetic effects of bariatric surgery. Ann Pharmacother. 2012; 46(1): 130-6. PMid:22190251. http://dx.doi.org/10.1345/aph.1Q414

[18] Jakobsen GS, Skottheim IB, Sandbu R, et al. Long-term effects of gastric bypass and duodenal switch on systemic exposure of atorvastatin. Surgical Endoscopy. 2013; 27(6): 20194101. PMid:23247745. http://dx . doi .org/10.1007/s00464-0 12-2716-3

[19] Darwich AS, Henderson K, Burgin A, et al. Trends in oral drug availability following bariatric surgery: examining the variable extent of impact on exposure of different drug classes. British Journal of Clinical Pharmacology. 2012; 75(5): 774-787. PMid:22463107. http://dx.doi .org/10.1111/j.1365-2125.2012.04284.x

[20] Chan LN. Drug therapy-related issues in patients who received bariatric surgery. Practical Gastroenterology. 2010; 34(7): 26-32.

[21] Miller AD, Smith KM. Medication use in bariatric surgery patients: what orthopedists need to know. Orthopedics. 2006; 29(2): 121-123. PMid:16485454.

[22] Sawaya RA, Jaffe J, Friedenberg L, et al. Vitamin, mineral, and drug absorption following bariatric surgery. Current Drug Metabolism. 
2012; 13(9): 1345-1355. PMid:22746302. http://dx.doi.org/1 $0.2174 / 138920012803341339$

[23] Bloomberg RD, Fleishman A, Nalle JE, et al. Nutritional deficiencies following bariatric surgery: what have we learned?. Obesity Surgery. 2005; 15: 145-154. PMid:15802055. http://dx.doi.o $\mathrm{rg} / 10.1381 / 0960892053268264$

[24] Brooks DR, Ben-Eltriki M, Gabr RQ, et al. The effects of gastric bypass surgery on drug absorption and pharmacokinetics. Expert Opinion on Drug Metabolism \& Toxicology. 2012; 9(12): 15051519. PMid:22998066. http://dx.doi.org/10.1517/1742525 5.2012 .722757

[25] Buxton IL, Benet LZ. Chapter 2. Pharmacokinetics: The dynamics of drug absorption, distribution, metabolism, and elimination. In L.L. Brunton, B.A. Chabner, B.C. Knollmann (Eds), Goodman \& Gilman's The Pharmacological Basis of Therapeutics, 2012; 12e. Available from: http://0-www.accessmedicine.com.librar y. simmons . edu/content . aspx?aID $=16658120$
[26] Huether SE. Structure and function of the digestive system. In McCance KL, Huether SE, Brashners VL, \& Rote NS (Eds). Pathophysiology: The Biologic Basis for Disease in Adults and Children. 2010.

[27] Padwall RS, Gabr RQ, Sharma AM, et al. Effect of gastric bypass surgery on the absorption and bioavailability of metformin. Diabetes Care. 2011; 34: 1295-1300. PMid:21478461. http://dx.doi.o $\mathrm{rg} / 10.2337 / \mathrm{dc} 10-2140$

[28] Thomas CM, Taub LM. Monitoring for and preventing the long-term sequelae of bariatric surgery. Journal AANP. 2010; (23): 449-458.

[29] Hamad GG, Helsel JC, Perel JM, et al. The effect of gastric bypass on the pharmacokinetics of serotonin reuptake inhibitors. American Journal of Psychiatry. 2012; 169(3): 256-63. PMid:22407114. http://dx.doi.org/10.1176/appi.ajp.2011.11050719

[30] Malone M. Altered drug disposition in obesity and after bariatric surgery. Nutrition in Clinical Practice. 2003; 18: 131-135. PMid:16215030. http://dx.doi.org/10.1177/01154265030 18002131 